\title{
Comprehensive analysis of the $M L H 1$ promoter region in 480 patients with colorectal cancer and 1150 controls reveals new variants including one with a heritable constitutional $M L H 1$ epimutation
}

\author{
Monika Morak, ${ }^{1,2}$ Ayseguel Ibisler, ${ }_{1}^{3}$ Gisela Keller, ${ }_{1}^{4}$ Ellen Jessen, ${ }^{5}$ Andreas Laner, ${ }_{1}^{2}$ \\ Daniela Gonzales-Fassrainer, ${ }^{2}$ Melanie Locher, ${ }^{2}$ Trisari Massdorf, $_{1}^{1}$ Anke M Nissen, ${ }^{2}$ \\ Anna Benet-Pagès, ${ }^{2}$ Elke Holinski-Feder ${ }^{1,2}$
}

- Additional material is published online only. To view please visit the journal online (http://dx.doi.org/10.1136/ jmedgenet-2017-104744).

${ }^{1}$ Medizinische Klinik und Poliklinik IV, Klinikum der Universität München, Munich, Bavaria, Germany

${ }^{2}$ Center of Medical Genetics, Medizinisch Genetisches Zentrum, Munich, Bavaria, Germany

${ }^{3}$ Department of Human Genetics, Ruhr University Bochum, Bochum, North RhineWestphalia, Germany ${ }^{4}$ Institute of Pathology, Technical University Munich, Munich, Bavaria, Germany

${ }^{5}$ Praxis für Humangenetik, Praxis für Humangenetik, Hamburg, Hamburg, Germany

\section{Correspondence to} Professor Elke Holinski-Feder, Center of Medical Genetics, Medizinisch Genetische Zentrum, Munich 80335, Germany; elke.holinski-feder@ mgz-muenchen.de

Received 17 April 2017 Revised 27 October 2017 Accepted 30 October 2017 Published Online First 22 February 2018

\begin{abstract}
Background Germline defects in MLH1, MSH2, MSH6 and PMS2 predisposing for Lynch syndrome (LS) are mainly based on sequence changes, whereas a constitutional epimutation of MLH1(CEM) is exceptionally rare. This abnormal MLH1 promoter methylation is not hereditary when arising de novo, whereas a stably heritable and variant-induced CEM was described for one single allele. We searched for MLH1 promoter variants causing a germline or somatic methylation induction or transcriptional repression.
\end{abstract}

Methods We analysed the MLH1 promoter sequence in five different patient groups with colorectal cancer (CRC) ( $n=480)$ composed of patients with i) CEM $(n=16)$, ii) unsolved loss of MLH1 expression in CRC $(n=37)$, iii) CpG-island methylator-phenotype CRC ( $n=102)$, iv) patients with $L S(n=83)$ and v) MLH1-proficient CRC $(n=242)$ as controls. 1150 patients with non-LS tumours also served as controls to correctly judge the results. Results We detected 10 rare MLH1 promoter variants. One novel, complex MLH1 variant C.-63_-58delins18 is present in a patient with CRC with CEM and his sister, both showing a complete allele-specific promoter methylation and transcriptional silencing. The other nine promoter variants detected in 17 individuals were not associated with methylation. For four of these, a normal, biallelic MLH1 expression was found in the patients' cDNA.

Conclusion We report the second promoter variant stably inducing a hereditary CEM. Concerning the classification of promoter variants, we discuss contradictory results from the literature for two variants, describe classification discrepancies between existing rules for five variants, suggest the (re-)classification of five promoter variants to (likely) benign and regard four variants as functionally unclear.

\section{INTRODUCTION}

Tumours with high microsatellite instability and immunohistochemical (IHC) loss of DNA mismatch repair (MMR) protein expression are hallmarks of Lynch syndrome (LS) following an autosomal dominant inheritance mode. ${ }^{1}$ The molecular basis of LS is a germline defect in one of the DNA MMR genes MLH1, MSH2, MSH6 or PMS2, classically due to a nucleotide change such as single nucleotide variants, small insertions or deletions (indels) or larger single/multiple exon deletions. ${ }^{2} 3$ In the rare condition of a constitutional epimutation of MLH1 (CEM), an abnormal MLH1 promoter methylation in all somatic tissues epigenetically causes a functional MLH1 defect. ${ }^{4-7}$ In addition to germline defects, the group of patients with MSI-H tumours lacking MLH1 protein staining also includes a substantial number of sporadic CRC cases showing $\mathrm{CpG}$-island methylator-phenotype (CIMP) and at least partial biallelic $M L H 1$ promoter methylation in tumour tissue only. ${ }^{8}$

Aberrant CEM is classically found hemiallelic and conducts transcriptional silencing of $M L H 1$ and EPM2AIP1. ${ }^{5-13}$ A 'primary' CEM is set-up de novo, ${ }^{12}{ }^{14-16}$ and is not heritable. The aberrant methylation is erased by the epigenetic reprogramming in germline formation, ${ }^{17}$ as shown in spermatozoa of CEM carriers ${ }^{71316}$ and in family members without methylation on the same allele. ${ }^{10} 12$ However, exceptional reports of CEM transmission to the next generation in single families might indicate an underlying genetic cause. ${ }^{1819}$ A 'secondary' CEM can be the consequence of a transcriptional repression, or might be induced by a variant in cis. ${ }^{20}$ In two cases with genomic deletions including the first exon of $M L H 1,{ }^{21} 22$ an allele-specific methylation of the remaining $M L H 1$ promoter was found. We previously reported one case of a CEM associated with a large genomic duplication. ${ }^{23}$ So far, one MLH1 promoter variant c.-27C>A in cis to variant c.85G $>$ T p.Ala29Ser has been reported for several patients with a CEM. ${ }^{162425}$ The allele with the variant showed an incomplete MLH1 promoter methylation ${ }^{16} 24$ and a reduced expression of MLH1. The mosaic CEM was reinstated on the variant allele in the next generation, ${ }^{1624}$ and in one family, the accumulation of CRC indicated a dominant trait of inheritance. ${ }^{25}$ In a reporter assay, variant c.-27A was designated to be causative for the reduced expression. ${ }^{16}$ Furthermore, promoter variants may also have regulatory effects without coincidence of methylation, as assumed, for example, for $M L H 1$ promoter variants c. $-11 \mathrm{C}>\mathrm{T}$, c. $-42 \mathrm{C}>\mathrm{T}$ and c. -413 -411delGAG reducing the promoter activity in varying degrees in luciferase reporter 
assays, ${ }^{25} 26$ and for variants c.-28A>G and c. $-7 \mathrm{C}>\mathrm{T}$ found in individuals with a partially reduced MLH1 gene expression. ${ }^{27}$

Our aim was to investigate the presence and effect of promoter variants that might impair the normal MLH1 gene function by either inducing a constitutional MLH1 epimutation in 16 patients with CEM, or by reducing the transcriptional activity in 37 patients with CRC with unsolved MLH1 deficiency in their tumours (H1D). Furthermore, we searched for promoter variants in patients with CIMP tumours and controls. We sequenced the $M L H 1$ promoter region at least up to $M L H 1$ c.-667 in a total of 480 patients with CRC divided into five molecular subgroups including controls, and 1150 patients with tumours not associated with LS (nLS) as a control group.

\section{MATERIALS AND METHODS}

Recruited patients gave informed consent for the study approved by the ethics committee in Munich. DNA from peripheral blood cells was extracted with the FlexiGene DNA kit (QIAGEN), from buccal cells, normal colon tissue and microdissected colon cancer tissue, the QIAamp DNA Blood Mini kit (QIAGEN) was used. Analyses for germline variants and large deletions/duplications in the genes MLH1 and PMS2, MSH2, EPCAM and MSH6 were performed as described previously. ${ }^{28} 29$

We investigated 238 patients with CRC with MLH1-deficient tumours in IHC staining divided into subgroups: i) 16 patients with a CEM (thereof, 12 were published, ${ }^{12}$ for details see online supplementary table 1), ii) 37 unsolved patients with MLH1-deficient tumour (H1D) and neither a germline variant in MLH1 or PMS2 nor MLH1 methylation found in blood and tumour DNA, iii) 102 patients showing at least 50\% MLH1 promoter methylation in their tumours (CIMP) and iv) 83 patients with LS with a pathogenic $M L H 1$ germline variant (class 4 or 5 according to InSiGHT). As controls, we investigated a patient with CRC group V of 242 patients with positive protein staining for MLH1 in their tumours (C-H1P) and 1150 tumour patients not suspicious of having LS (C-nLS) (see table 1).

The promoter analysis was performed by Sanger sequencing from $M L H 1$ c. -667 to c. $116+40$ (g. $37034372-37035194$ ) as described $^{12}$ and was extended for the CEM carriers to a region
$5 \mathrm{~kb}$ upstream of MLH1 by Long-Range PCR (TAKARA) to cover also potentially regulatory regions further upstream as the promoter region is not clearly defined. The controls were analysed by next-generation sequencing using the TruSight Rapid Capture and TruSight Cancer Sequencing Panel (Illumina) covering the MLH1 promoter until c.-667. With MS-MLPA kit ME011 (MRC Holland), the MLH1 promoter region from c. -659 to c. $116+90$ was tested for larger genomic deletions, duplications and for methylation. Sodium bisulfite treatment of genomic DNA, methylation-specific PCR amplification of two overlapping fragments in the $\mathrm{MLH} 1$ promoter region from c.-362 to c. -193 and from c. -286 to c. 17 spanning 22 CpG dinucleotides and sequencing was performed as published. ${ }^{12}$

For cDNA analyses, total RNA was extracted from peripheral blood cells by the PAXGene Blood RNA and Preparation kit (PreAnalytix), and from lymphocytes cultured after Ficoll separation with and without puromycin incubation to check nonsense-mediated mRNA decay. The cDNAs were generated with iScript select cDNA-Synthesis kit (Bio-Rad) using an oligo $(\mathrm{dT})_{18}$ primer. Biallelic expression of genomically heteroyzgous variants was investigated for EPM2AIP1, MLH1 and LRRFIP2 by PCR amplification followed by digestion with Exo-SAP kit (USB) and Sanger sequencing with Big Dye V.1.1 (Applied Biosystems) on ABI PRISM 3100 Avant using additional primers for sequencing, as we described. ${ }^{23}$ The longer transcript of MLH1 was amplified from c.-148 or c.-113 to c.883 with primers spanning the 5 'UTR (untranslated region) to exon 10 by standard procedures with LongAmp Taq (NEB) as described. ${ }^{23}$ For cDNA analysis of EPM2AIP1, fragments were amplified from c.-84 or c.-227 to c.197, or within the 3'UTR from c. ${ }^{2} 2470$ to c. "2630 using Ampli-Taq Gold (ABI) at standard procedures. ${ }^{30}$ In parallel, genomic contamination in cDNA was ruled out by PCR with primers in MLH1 exon 7 forward and eight reverse spanning a small genomic intron and analysis on a $1 \%$ agarose gel, as otherwise, cDNA analysis would be invalid for EPM2AIP1 due to a lack of introns. The transcript of LRRFIP2 was amplified from c.1988 to c."300 using Ampli-Taq Gold (ABI) at standard procedures. ${ }^{30}$ By using informative variants we investigated the allelic distribution of MLH1, EPM2AIP1

Table 1 Patients groups and results

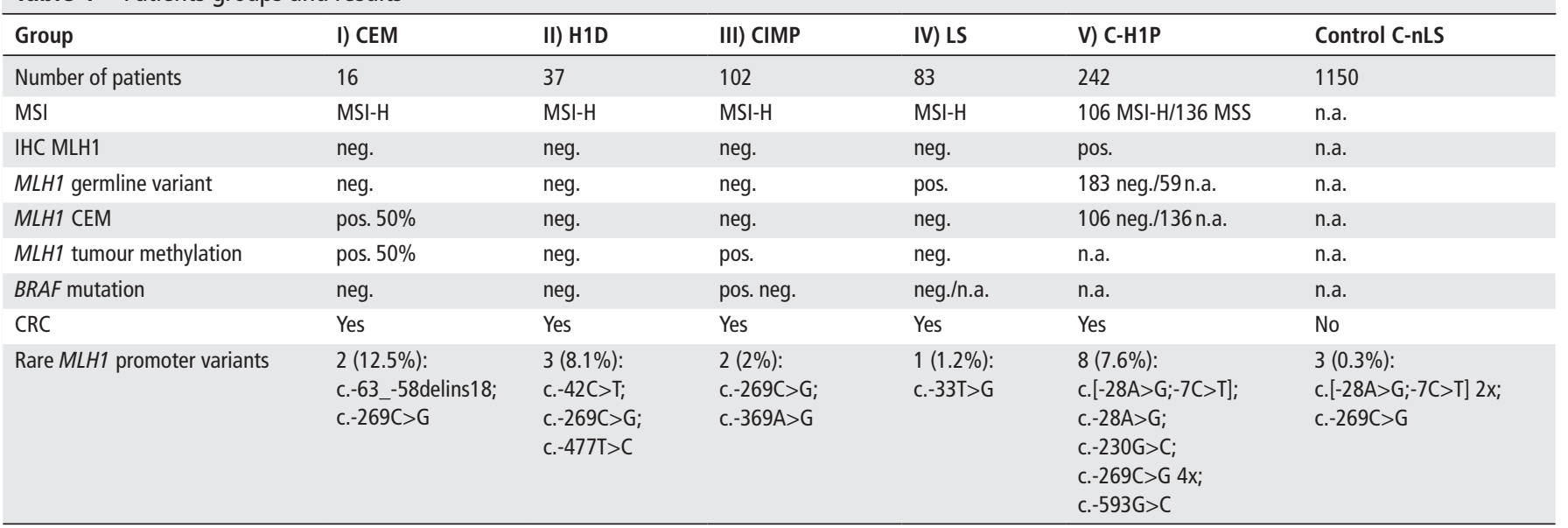

Categorisation of 1630 patients into different groups by molecular characteristics including the status of microsatellite instability (MSI), immunohistochemical staining (IHC) of MLH1 in the tumour (positive: pos., negative: neg.), MLH1 germline variants, methylation of the MLH1 promoter in blood (CEM) and in tumour, BRAF mutation status in NM_004333.4 c.1799T>A p.Val600Glu in the tumour and diagnosis of colorectal cancer (CRC). Not analysed: $n$.a. 480 patients with CRC were subdivided into groups I-V, of those, I-IV had MLH1-deficient tumours of different causes: I) constitutional MLH1 epimutation (CEM), II) unsolved MLH1-deficiency in the tumour (H1D), III) CIMP tumours, IV) patients with Lynch syndrome (LS) with pathogenic MLH1 germline variants (class 4 or 5 according to InSiGHT). Group V consists of 242 patients with MLH1-proficient tumours (C-H1P) and served as a control group. The second control group (C-nLS) comprises patients with tumours indicating other syndromes, but not LS. The number of rare promoter variants detected in each group (and their percentage in brackets) is given and variant nomenclature is provided in relation to the MLH1 translation start. 


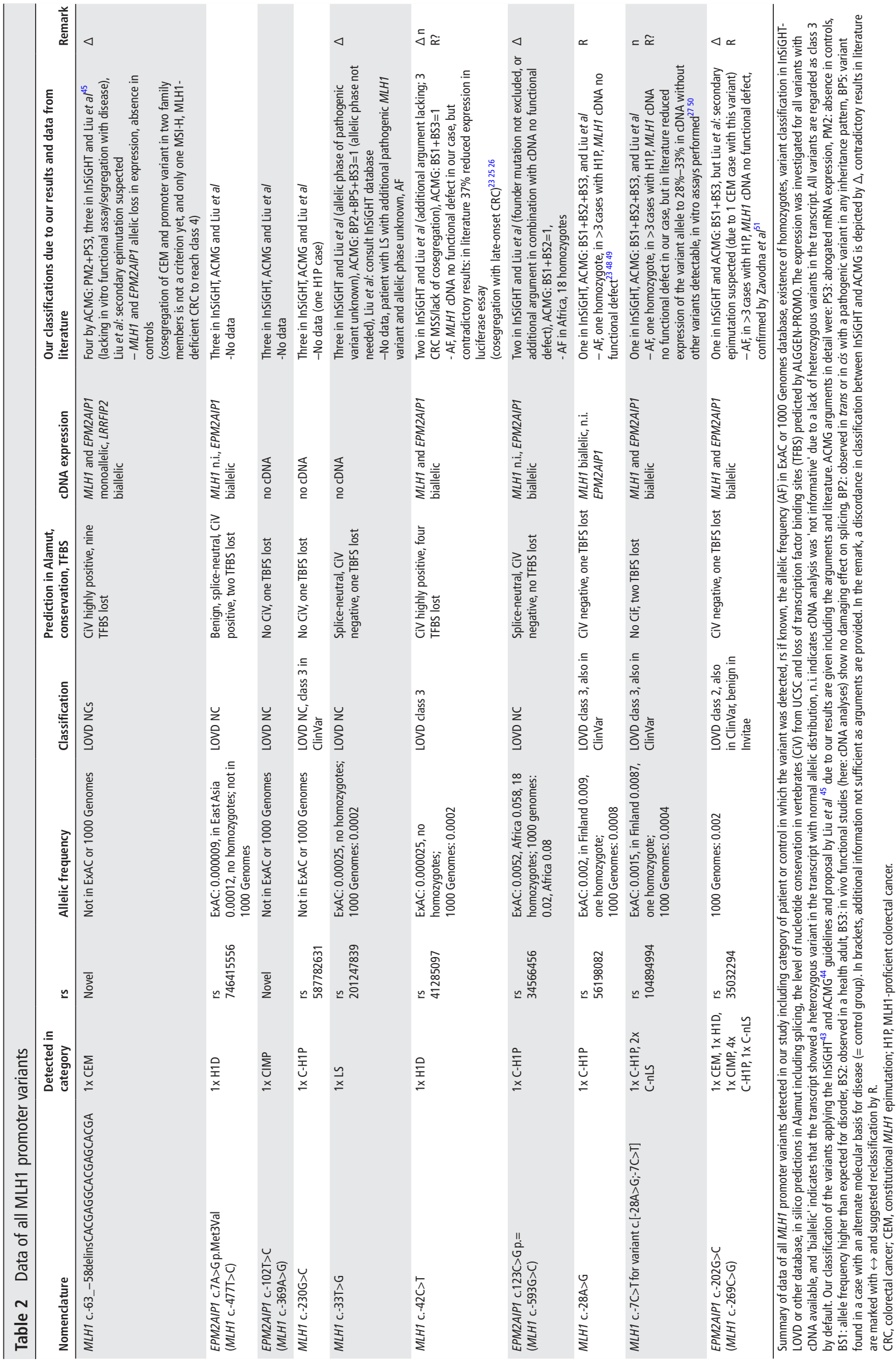


$1 \mathrm{~A}$

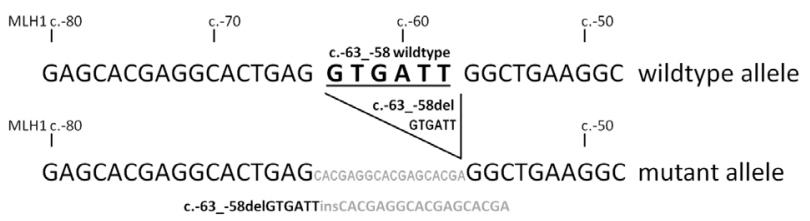

c.-63 -58delGTGATTIIISCACGAGGCACGAGCACGA

$1 \mathrm{~B}$

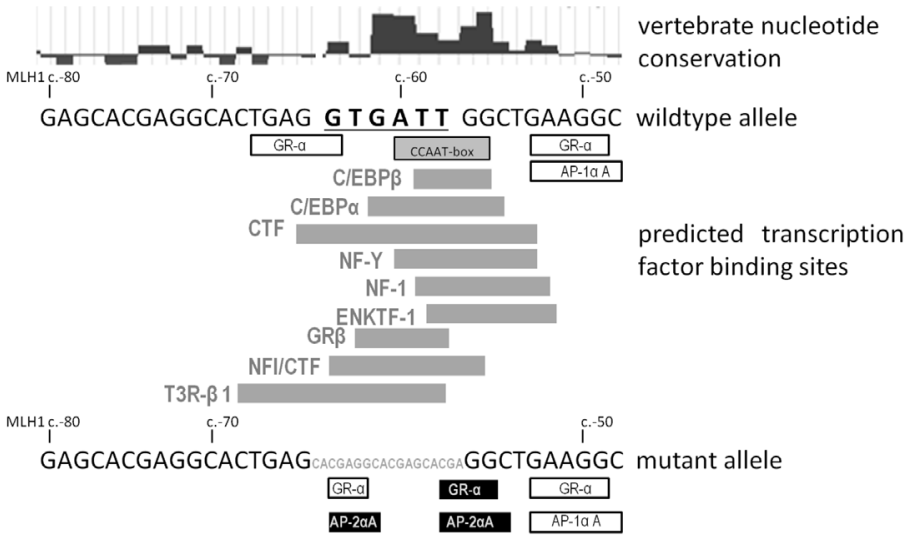

$1 \mathrm{C}$

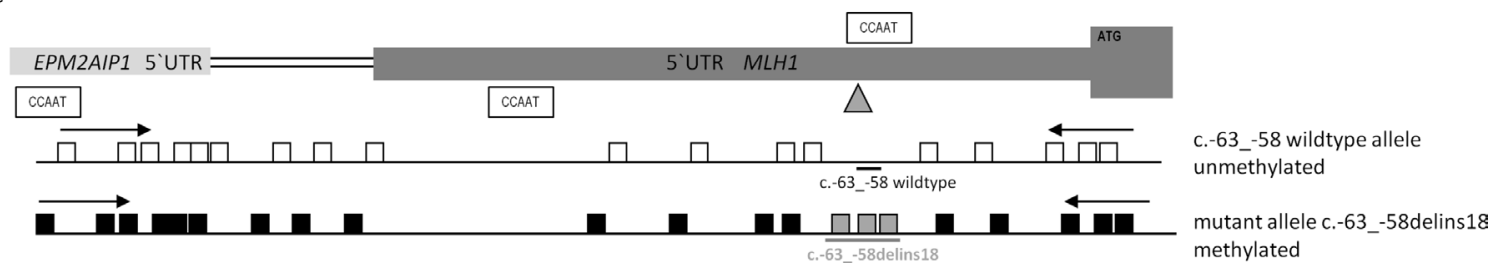

Figure 1 (A) Schematic diagram of the genomic alleles of the MLH1 promoter in patient CEM-15 harbouring the complex heterozygous variant c.63_-58 delGTGATTinsCACGAGGCACGAGCACGA or C.-63_-58delins18 in the 5'UTR of the MLH1 transcript. The wild-type allele above shows six bases in bold, which are deleted in the mutant allele below. Instead, the mutant allele contains an insertion of 18 nucleotides (written in grey). (B) Diagram of vertebrate nucleotide conservation (UCSC Genome Browser), predicted transcription factor binding sites (TFBS, by ALGGEN-PROMO), a CCAAT-box in the complementary reverse strand of the wild-type allele in bold and changes in the mutant allele (written in grey) below. Grey filled boxes indicate lost TFBS due to the variant, white boxes show preserved TFBS and black boxes depict newly generated TFBS in the mutated allele. (C) Schematic illustration of bisulfite sequences. The germline promoter methylation of 50\% was also investigated with methylation-specific primers in bisulfite-converted DNA of the patient. Selection for unmethylated alleles (open boxes) presented only the wild-type allele (underlined in black). Sequencing of the methylated fragments below detected complete methylation (filled boxes) in all $15 \mathrm{CpG}$ dinucleotides analysed in the fragment, which specifically show only the variant allele c.63_-58delins 18 (depicted and underlined in grey).

and LRRFIP2 transcripts in presence of the promoter variant. Primer sequences are available on request.

For sequence analysis, the Mutation Surveyor V.3.1 (SoftGenetics) software was used. For annotation we refer to the RefSeq transcripts NM_000249.3, NG_007109.2 for MLH1, NM_014805.3, NG_008418.1 for EPM2AIP1 and NM_006309.3, NC_000003.11 for LRRFIP2 on Chr.3 (GRCh37); nomenclature is given according to HGVS standard recommendations V.2016 (http://varnomen.hgvs.org/ recommendations) $)^{31}$ referring to the genomic positions in hg19. Alamut V.2.6.1 was used for variant interpretation, as well as allelic frequencies in different populations (ExAC browser and 1000 Genomes). The evolutionary nucleotide conservation in vertebrates was derived from UCSC Genome Browser. For the prediction of transcription factor binding sites abolished by promoter variants, we applied the ALGGEN-PROMO tool V.3. $0^{32}$ with preselection to only human factors and human sites in a 'Search Promotor Sites' mode using standard parameters for sequences including 10 nucleotides around the promoter variant and compared the wild-type with the variant. Additionally, the generation of new translational start codons by promoter variants was ruled out. The MLH1 promoter variants identified have been submitted to the InSiGHT MMR gene variant database LOVD3 (http://www.insight-group.org/variants/database/). ${ }^{3}$

\section{RESULTS}

By sequencing the MLH1 promoter in a total of 1630 individuals including patients with CRC and controls, we detected 10 different rare $M L H 1$ promoter variants (table 1 ). The heterozygous allelic presence of the frequent variant c.-93G $>$ A oscillated between 33\% and 51\% depending on the group analysed.

\section{Promoter variants in patients with constitutional $M L H 1$ epimutation}

Within the 16 patients with LS due to a constitutional MLH1 epimutation (CEM), we detected two rare MLH1 promoter variants: the novel, complex variant c.-63_-58delGTGATTinsCACGAGGCACGAGCACGA (from now on referred to as c.-63_-58delins18) was found in patient CEM-15 (see figure $1 \mathrm{~A}$ and online supplementary figure $1 \mathrm{~A}$ ), and variant c.-269C>G in patient CEM-6 (see table 1 and online supplementary table 


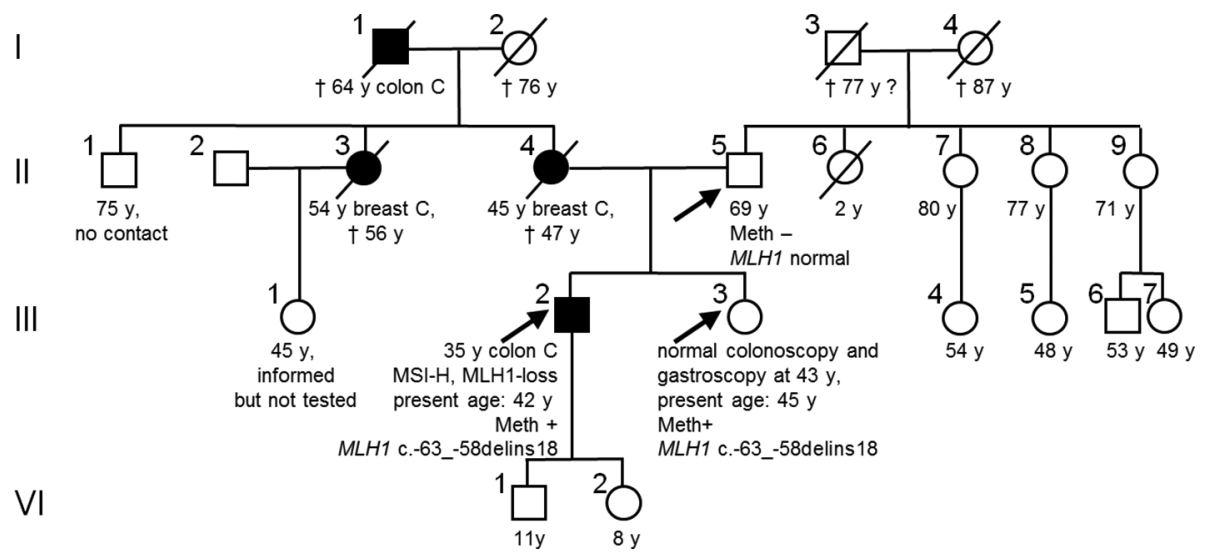

Figure 2 Family pedigree of patient CEM-15. Tumours ( $C=$ cancer) are given at age of diagnosis in years (y), and age at death is indicated by $t$. Blood samples were available from the index patient III-2, his sister and his father (indicated by arrows). The constitutional MLH1 epimutation (Meth+) is linked to the MLH1 variant c.-63_-58delins 18 and is present in the index patient and the sister, whereas the father reveals the normal promoter sequence and no methylation (Meth-).

1, and details in table 2). Variant c.-269C>G was also found in seven further patients without CEM (see below). The common variant c.-93G $>$ A was present heterozygously in eight patients with CEM, and homozygously in one patient with CEM. By MS-MLPA, no CNV was detected in the promoter region for 14 CEM cases, 1 large duplication was described previously ${ }^{23}$ and 1 case could not be analysed.

For patient CEM-15, the MLH1 promoter methylation of approximately $50 \%$ of alleles in all $\mathrm{CpG}$ dinucleotides investigated by MS-MLPA was found in peripheral blood cells, buccal cells, normal colon tissue and in his colon adenocarcinoma diagnosed at the age of 35 years, as well as in peripheral blood cells and buccal cells of his sister. The father was tested negative for both CEM and the promoter variant in peripheral blood, and no tumour diagnoses were reported in the paternal line of the family (for pedigree and clinical data see figure 2). No DNA was available from the mother who died at the age of 47 years after diagnosis with breast cancer, the maternal aunt with breast cancer diagnosed at the age of 54 years or the maternal grandfather who died from colon cancer at the age of 64 years.

No segregation analysis was possible for patient CEM-6 with MLH1 promoter variant c. $-269 \mathrm{C}>\mathrm{G}$, and nine other CEM cases. With the segregation and transmission analyses of the four other CEM index patients (details in online supplementary table 1), we found a de novo methylation of the maternal allele in two families, and observed the erasure of the CEM from the paternal allele when transmitted to their sons in two other families. CEM was previously shown to be inherited in one family in association with a large duplication. ${ }^{23}$

After bisulfite conversion and amplification specifically for methylated alleles, the patient CEM-15 and his sister showed a $100 \%$ complete methylation of all $15 \mathrm{CpG}$ dinucleotides covered, which were specific for the MLH1 variant allele c.-63_-58delins18 (schematic figure 1C, sequence electropherograms in online supplementary figure $2 \mathrm{~B}$ ). In the PCR for unmethylated alleles of patient CEM-15 and his sister, only the MLH1 promoter wild-type allele was represented (see online supplementary figure $2 \mathrm{C}$ ). In the father with wild-type at c.-63 58 , we could amplify two unmethylated alleles, as these were informative for the heterozygous promoter variant c.-93G $>$ A (see online supplementary figure 2C). Bisulfite sequencing in patient CEM-6 revealed complete methylation in all $\mathrm{CpG}$ dinucleotides analysed, which was specific for the variant allele MLH1 c.-269G, whereas the wild-type allele c.-269C was unmethylated.

We performed cDNA analyses for MLH1, EPM2AIP1 and LRRFIP2 transcripts from RNA isolated from PAXgene and short-term lymphocyte cultures with and without puromycine incubation prior to RNA-isolation from patient CEM-15 and his sister. For MLH1 only the wild-type allele was expressed (see online supplementary figure 1C), whereas the variant c. -63 -58delins 18 located in the 5'UTR of the MLH1 transcript was not detectable in any cDNA of the two siblings. EPM2AIP1 also showed a monoallelic expression of only the $\mathrm{T}$ allele in cDNAs of both siblings (see online supplementary figure $1 \mathrm{C})$ in the genomically heterozygous variant c. $* 2570 \mathrm{G}>\mathrm{T}$ in the 3'UTR. For LRRFIP2, a biallelic expression was found in patient CEM-15 and his sister by analysing the heterozygous variant c. $* 272 \mathrm{G}>\mathrm{A}$ in the 3 'UTR. For patient CEM-6 harbouring variant $M L H 1$ c. $-269 \mathrm{C}>\mathrm{G}$, no RNA was available, but cDNA analyses were performed in another person with this variant diagnosed with a CIMP tumour (results in section: "Promoter variants in other patients with CRC and controls" and table 2).

\section{Promoter variants in other patients with CRC and controls}

Sequencing the MLH1 promoter in 1614 further individuals, we identified nine rare $M L H 1$ promoter variants in 17 cases: c. $-593 \mathrm{G}>$ C, c. $-477 \mathrm{~T}>$ C, c. $-369 \mathrm{~A}>\mathrm{G}$, c. $-269 \mathrm{C}>\mathrm{G}$, c. $-230 \mathrm{G}>\mathrm{C}$, c. $-42 \mathrm{C}>\mathrm{T}$, c. $-33 \mathrm{~T}>\mathrm{G}$, c. $-28 \mathrm{~A}>\mathrm{G}$, c. $[-28 \mathrm{~A}>\mathrm{G} ;-7 \mathrm{C}>\mathrm{T}]$ (table 1 , details in online supplementary figure $1 \mathrm{~A}$ ). These variants were found in three patients with unsolved MLH1 deficiency (H1D), one patient with a pathogenic $M L H 1$ germline variant c.793C > T (LS), two CIMP cases, eight patients with MLH1-proficient CRC (C-H1P) and three controls without LS-tumours (C-nLS) (see table 2). Four of these promoter variants were previously listed in LOVD, and assigned MLH1 c. $-42 \mathrm{C}>\mathrm{T}$, c. $-28 \mathrm{~A}>\mathrm{G}$ and c. $-7 \mathrm{C}>\mathrm{T}$ as class 3 , and c. $-269 \mathrm{C}>\mathrm{G}$ as class 2 (table 2). The allele c. [-28A $>\mathrm{G} ;-7 \mathrm{C}>\mathrm{T}]$ was represented in three control cases. Methylation in the MLH1 promoter was absent in blood DNA of all 17 patients with one of the nine rare MLH1 promoter variants. To rule out tissue-specific methylation set-up in colon, colonic normal mucosa was investigated and found methylation-negative for all six variants c.-477T $>$ C, c.-369A $>$ G, 
c. $-269 \mathrm{C}>\mathrm{G}$, c. $-230 \mathrm{G}>\mathrm{C}$, c. $-42 \mathrm{C}>\mathrm{T}$ and c. $-33 \mathrm{~T}>\mathrm{G}$ in seven cases with tissue available.

To investigate the effect of promoter variants on mRNA generation on the respective allele in vivo, we analysed the allelic balance of genomically heterozygous variants in the transcripts of MLH1 and EPM2AIP1 by sequencing. For six of these promoter variants RNA of patients with at least one informative variant in MLH1 or EPM2AIP1 could be obtained (see online supplementary figure 1C). A biallelic expresssion of EPM2AIP1 was found for MLH1 promoter variants c.-593G>C and c. $-477 \mathrm{~T}>\mathrm{C}$, which are both located in the coding region of EPM2AIP1, whereas MLH1 was not analysable due to a lack of informative variants. A biallelic expression was found in cDNA analyses for $M L H 1$ promoter variants c. $-269 \mathrm{C}>\mathrm{G}$ c. $-42 \mathrm{C}>\mathrm{T}$ and c. $[-28 \mathrm{~A}>\mathrm{G} ;-7 \mathrm{C}>\mathrm{T}]$ for both EPM2AIP1 and MLH1 in all cDNAs, and for variant c. $-28 \mathrm{~A}>\mathrm{G}$ without c. $-7 \mathrm{C}>\mathrm{T}$ in $c$ is for $M L H 1$, without informative variants for EPM2AIP1. For the frequent promoter variant c.-93G $>$ A, we performed cDNA analyses of three homozygote and 15 heterozygote controls, and found a biallelic expression of both transcripts EPM2AIP1 and MLH1 in all patient cDNAs. No RNA was available from patients with $M L H 1$ promoter variants c. $-369 A>G$, c. $-230 G>C$ and c. $-33 \mathrm{~T}>\mathrm{G}$.

\section{DISCUSSION}

MLH1 and EPM2AIP1 are bidirectionally paired genes with a shared promoter region. The core promoter region for $M L H 1$ has been defined from c. -184 to c. $-132,{ }^{33}$ whereas additional cis elements and essential protein binding sites were defined from c. -301 to c. $-76 .{ }^{34}$ The transcriptional activity of the MLH1 promoter strongly depends on two CCAAT boxes located in c. $-278-282$ and c. $-145-141$ from the MLH1 translation start, ${ }^{34-36}$ for EPM2AIP1 a complementary reverse CCAAT box is located in the MLH1 5'UTR at c.-56_-60. Furthermore, the regions from c. -250 to c. $-151 \mathrm{bp}^{3637}$ and from c. -273 to c. $-4^{38}$ are described as critical for the regulation of MLH1 transcription. Promoter variants have the potential to reduce or abrogate the transcriptional activity either with ${ }^{162425}$ or without $^{25}$ an allele-specific promoter methylation, and might be tissue-specific.

We searched for causative $M L H 1$ promoter changes within at least MLH1 c. -667 and c. $116+40$ in 16 patients with CEM and 37 patients with unsolved H1D. To better judge the variants, we also analysed 102 patients with CIMP tumours, 83 patients with LS, 242 patients with H1P and 1150 patients with non-LS tumours (nLS). We detected a total of 10 different rare MLH1 promoter variants in 1630 individuals (table 1). One variant is associated with a heritable CEM. Six of our 10 variants were not listed in LOVD before, and 2 were regarded as novel. The incidence rates of promoter variants differed between $12.5 \%$ and $0.3 \%$, but the association of a variant with CEM or unsolved MLH1-deficient patients with CRC did not reach a statistical significance due to small case numbers.

\section{Promoter variants associated with an epimutation}

A CEM is regarded not to be heritable for cases in which the methylation was set-up de novo by chance. However, cis-acting germline variants may induce a stably inherited CEM. So far, only one MLH1 allele c. $-27 \mathrm{C}>\mathrm{A}$ in cis with c. $85 \mathrm{G}>\mathrm{T}$ was found in several families association with a heritable mosaic CEM and reduced transcriptional expression. ${ }^{162425}$ In our 16 patients with CEM, we sequenced the $M L H 1$ promoter and regulatory region up to $5 \mathrm{~kb}$ upstream of the MLH1 transcription start and identified two rare variants in one patient each.
We report the novel MLH1 promoter variant c.-63_-58delins18 in 1 of 16 patients with CEM, which is for the first time associated with a complete promoter methylation in tissues from ectodermal and mesodermal germ layers and transcriptional silencing of the variant allele for MLH1 and EPM2AIP1 in the index patient and his sister. This variant was probably inherited from the mother who died of breast cancer and had a family history for breast and colon cancer. We have evidence that MLH1 promoter variant c. -63 - 58 delins 18 causes a secondary CEM following a stable, autosomal-dominant inheritance, and offered predictive testing for related family members at the age of majority.

So far, only one MLH1 promoter variant c.-27C > A 16242527 and one large genomic duplication ${ }^{23}$ were reported to induce a heritable, secondary CEM, but both were associated with mosaic methylation.

The mechanism causing the heritable CEM in our patient remains unclear, as no in vitro assays have been performed. Methylation can be induced as a consequence of transcriptional silencing, as shown for MSH2 in patients with EPCAM deletions, ${ }^{39}$ and for genomic deletions including $M L H 1$ exon $1 .^{21} 22$ Taking into account the high evolutionary conservation, the predicted loss of nine TFBS including NF-Y in a critical regulatory region, ${ }^{38}$ and the loss of a CCAAT-box consensus sequence (see online supplementary figure $1 \mathrm{~B}$ ), the transcriptional silencing of either MLH1 or EPM2AIP1 by regulatory effects might have induced methylation of the shared promoter region as a secondary consequence. Alternatively, a variant-directed methylation of the DNA could be hypothesised, ${ }^{20}$ or a variant-specific change of the histone modifications compacting the chromatin conformation could be taken into account. ${ }^{40}{ }^{41}$ However, this effect is limited to MLH1 and EPM2AIP1 as reflected by a monoallelic expression in cDNA analyses, while LRRFIP1 downstream of MLH1 shows a biallelic expression in our patient.

For another epimutation carrier, we detected the MLH1 variant c.-269C>G. Even though the variant allele was methylated here, in another case in literature the wild-type allele was methylated, ${ }^{25}$ arguing against a variant-specific CEM induction. Furthermore, we detected c.-269C $>$ Galso in seven individuals without CEM.

The heritability of CEM was not investigable for this and nine other CEM cases. In four families a primary constitutional MLH1 methylation is suspected, as a de novo set-up of methylation or an erasure of methylation in children could be demonstrated. For one family a secondary CEM in combination with a large duplication was published previously, ${ }^{23}$ whereas no CNV was detected in 14 CEM cases.

\section{Promoter variants without epimutation}

MLH1 promoter variants may have the potential to abrogate TFBS, generate transcriptional repressors or change the chromatin status and by these means have an impact on the transcription, but do not necessarily induce methylation. In literature, MLH1 promoter variants c. $-11 \mathrm{C}>\mathrm{T}$, c. $-27 \mathrm{C}>\mathrm{A}$, c. $-42 \mathrm{C}>\mathrm{T}$, c.-413_-411delGAG and c.-435_-432delAAAG were reported in patients without CEM, but alleles c.-11T, c.-27A and c.-42T significantly reduced the promoter activity in luciferase assays. ${ }^{25}$

In 17 individuals without CEM, we detected 9 MLH1 promoter variants (c.-593G $>$ C, c. $-477 \mathrm{~T}>\mathrm{C}$, c. $-369 \mathrm{~A}>\mathrm{G}$, c. $-269 \mathrm{C}>\mathrm{G}$, c. $-230 \mathrm{G}>\mathrm{C}$, c. $-42 \mathrm{C}>\mathrm{T}$, c. $-33 \mathrm{~T}>\mathrm{G}$, c. $-28 \mathrm{~A}>\mathrm{G}$ and c. $[-28 \mathrm{~A}>\mathrm{G} ;-7 \mathrm{C}>\mathrm{T}]$ ) (tables 1 and 2 ), which seem to be quite infrequent in LOVD and literature. ${ }^{342}$ We regard the biallelic gene expression of MLH1 but not EPM2AIP1 as a significant 
argument for the classification of promoter variants in patients suspected of having LS. The MLH1 cDNA analyses informative for four variants showed no evidence of a reduced transcriptional activity.

\section{Promoter variant prediction, classification and interpretation}

So far, no specific rules for the classification of promoter variants have been described by the current InSiGHT or ACMG scheme, neither in presence nor in absence of CEM, ${ }^{43} 44$ but the necessity is already underscored in a pioneer publication. ${ }^{45}$ Only with criteria such as a high population frequency and/ or homozygous state in healthy controls it is possible to reach a benign or likely benign classification, as it was the case for our MLH1 promoter variant c. $-593 \mathrm{G}>\mathrm{C}$. The exception is one promoter variant in $\mathrm{MSH} 2$ c. -78 - $77 \mathrm{delGT}$, which was graded as class 4 -likely pathogenic in LOVD. ${ }^{46}$ For the classification of our 10 rare promoter variants identified, we apply the fivetiered InSiGHT scheme, ${ }^{43}$ ACMG guidelines ${ }^{44}$ and the guide proposed by Liu et $a l^{45}$ (results compiled in table 2), and suggest amendments specific for promoter variants. The loss of TFBS and the nucleotide conservation in vertebrates (depicted in online supplementary figure $1 \mathrm{~B}$ ) are listed in table 2, but have no consented predictive value. We therefore only used our cDNA results, allelic frequency and presence in patients with CRC with or without MMR defect as criteria for the classification.

In our attempt to classify the MLH1 promoter variant c.-63_-58delins18 we detected in two siblings with an epimutation, we would reach class 4-likely pathogenic with the ACMG criteria, but only class 3-uncertain significance as CEM is not included in the current InSiGHT classification rules and Liu et $a l^{45}$ due to the lack of functional tests (table 2). This outstanding work addressing the problem of promoter variant classification and interpretation is regarding a CEM as secondary and heritable if a promoter variant is detected. ${ }^{45}$ We nevertheless suggest to investigate the heredity of CEM for each case, also in absence of promoter variants. For a class 4 classification of a promoter variant like ours associated with a CEM, we would recommend to add to the InSiGHT guidelines: 'In constitutional promoter methylation carriers, the allele with the promoter variant has to be proven to be methylated allele and/or an allele-specific transcriptional silencing has to be demonstrated and/or a segregation with the promoter variant and a constitutional MLH1 promoter methylation in a family is shown'. To reach a class 5 for promotor variants, we would agree with Liu et $a l^{45}$ to add: 'For regulatory defects, the allele-specific silencing has to be confirmed in an in vitro functional assay'.

The nine further MLH1 promoter variants c.-593G $>\mathrm{C}$, c. $-477 \mathrm{~T}>\mathrm{C}$, c. $-369 \mathrm{~A}>\mathrm{G}$, c. $-269 \mathrm{C}>\mathrm{G}$, c. $-230 \mathrm{G}>\mathrm{C}$, c. $-42 \mathrm{C}>\mathrm{T}$, c. $-33 \mathrm{~T}>\mathrm{G}$, c. $-28 \mathrm{~A}>\mathrm{G}$ and c. $[-28 \mathrm{~A}>\mathrm{G}$;-7C $>\mathrm{T}]$ were not causatively associated with CEM in 17 individuals. The AF of variant c.-593G > C in Africans allowed a classification to class 2-likely benign. With the intention to classify the other promoter variants, we interpreted the biallelic cDNA expression of $M L H 1$ equivalent to the InSiGHT argument 'with no associated mRNA aberration' (table 2), but to reach a class 2, an additional argument is needed. Alternatively, it could be discussed whether promoter variants can be put equal to synonymous substitutions, as both do not change the coding transcript, and reach class 2 only by showing absence of mRNA aberration. However, Liu et al suggest an additional criterion in combination with 'absence of allelic loss in vivo', ${ }^{45}$ which we strongly support to reach class 1.

Based on our normal cDNA results and presence in controls with MLH1-proficient CRC, we would suggest a reclassification from class 3 to class 1 for the three $M L H 1$ promoter variants (c. $-269 \mathrm{C}>\mathrm{G}$, c. $-28 \mathrm{~A}>\mathrm{G}$ and c. [-28A $>\mathrm{G}$; $-7 \mathrm{C}>\mathrm{T}]$ ), and to class 2 for one variant (c. $-42 \mathrm{C}>\mathrm{T}$ ). Four variants (c. $-477 \mathrm{~T}>\mathrm{C}$, c. $-369 \mathrm{~A}>\mathrm{G}$, c. $-230 \mathrm{G}>\mathrm{C}$ and c.-33T $>\mathrm{G}$ ) with insufficient data remain class 3 - of uncertain significance.

The classification of our promoter variants gave divergent results between InSiGHT and ACMG for five variants (table 2). Our impression is that with the ACMG rules a meaningful classification can be reached more easily_and might be subject to revision, whereas the InSiGHT guidelines require more evidence and are quite definite.

For the MLH1 promoter variants c. $-42 \mathrm{C}>\mathrm{T}$ and c. [-28A $>\mathrm{G}$;$7 \mathrm{C}>\mathrm{T}]$, contradictory findings are reported in the literature. ${ }^{2627}$ We observed a normal biallelic representation of heterozygous variants in cDNA by PCR and Sanger sequencing, which is not a quantitative method, but is capable to show major allelic imbalances, as well as allelic losses. ${ }^{23}$ We cannot explain the conflicting results reported as partial allelic imbalance and reduced expression in luciferase assays, ${ }^{25-27}$ which also exist for variant c. $-93,{ }^{47}$ and might be attributable to different isoforms, or additional pathogenic variants. So far, no clear procedure is provided for contradictory results by the InSiGHT classification rules, and a threshold definition for a reduced promoter activity in functional assays or a reduced cDNA expression and their interpretation is also claimed by Liu et al..$^{45}$ Furthermore, the necessity to investigate expression analyses in colon mucosa has to be discussed on international level, as this is one of the target tissues for LS, and might also attribute for splicing analyses of variants in general.

To sum up, we describe 10 different rare MLH1 promoter variants. The novel MLH1 promoter variant c.-63_-58delins 18 was found in one of our 16 epimutation carriers. We report the second MLH1 promoter variant associated with a secondary, heritable CEM in in two siblings, and the first variant showing full methylation and complete transcriptional silencing. Promoter variant c.-27C $>$ A was previously reported in association with an incomplete, mosaic promoter methylation and a reduced $M L H 1$ gene expression. ${ }^{162427}$ For nine other MLH1 promoter variants identified in patients and controls, no variant-specific promoter methylation was detected, and in informative cases a normal MLH1 transcription was found for four variants.

For variant c.-63_-58delins18 associated with a heritable CEM, we would suggest class 4, assign four variants to class 3 , and based on our results we would (re-)classify five MLH1 promoter variants c. $-593 \mathrm{G}>\mathrm{C}$, c. $-269 \mathrm{C}>\mathrm{G}$, c. $-42 \mathrm{C}>\mathrm{T}$, c. $-28 \mathrm{~A}>\mathrm{G}$ and c. $[-28 \mathrm{~A}>\mathrm{G} ;-7 \mathrm{C}>\mathrm{T}]$ as class 1 or 2 .

Variants with an impact on transcription or inducing a stably heritable CEM are only rarely identified in the $M L H 1$ promoter region. However, internationally approved rules are needed for a standardised classification of MMR promoter variants, which have to be discussed and amended on international level by the InSiGHT interpretation committee.

Acknowledgements The authors thank the German Cancer Aid (Deutsche Krebshilfe) and the Wilhelm Sander-Stiftung for their support of this work. The authors also thank all patients for their participation in this study, as well as their respective doctors for contributing materials and clinical information.

Contributors EH-F and MM designed the study, wrote the manuscript and are responsible for the content of the study. EH-F, Al, GK, EJ and DG-F provided patients clinical and molecular data and samples. Experiments were mainly performed by TM, supervised by MM; tumour analyses were also carried out by $M L$ and $A L$. AB-P was responsible for NGS techniques and supervised AMN for bioinformatical analyses. $E H-F, M M, A L, A B-P$ and $A N$ were involved in data analyses and interpretation. $E H-F$ and $\mathrm{MM}$ wrote the manuscript and are responsible for the content of the study. MM submitted the article. 
Funding This work was supported by grants from the German Cancer Aid (Deutsche Krebshilfe) (\#111222) and the Wilhelm Sander-Stiftung (\#2012.081.1).

Competing interests None declared.

Patient consent Obtained.

Ethics approval Ethikkommission der Medizinischen Fakultät der LMU München.

Provenance and peer review Not commissioned; externally peer reviewed.

(c) Article author(s) (or their employer(s) unless otherwise stated in the text of the article) 2018. All rights reserved. No commercial use is permitted unless otherwise expressly granted.

\section{REFERENCES}

1. Lynch HT, de la Chapelle A. Genetic susceptibility to non-polyposis colorectal cancer. J Med Genet 1999;36:801-18.

2. Mangold E, Pagenstecher C, Friedl W, Mathiak M, Buettner R, Engel C, Loeffler M, Holinski-Feder E, Müller-Koch Y, Keller G, Schackert HK, Krüger S, Goecke T, Moeslein G, Kloor M, Gebert J, Kunstmann E, Schulmann K, Rüschoff J, Propping P. Spectrum and frequencies of mutations in MSH2 and MLH1 identified in 1,721 German families suspected of hereditary nonpolyposis colorectal cancer. Int $J$ Cancer 2005; 116:692-702

3. Plazzer JP, Sijmons RH, Woods MO, Peltomäki P, Thompson B, Den Dunnen JT, Macrae F. The InSiGHT database: utilizing 100 years of insights into Lynch syndrome. Fam Cancer 2013:12:175-80

4. Gazzoli I, Loda M, Garber J, Syngal S, Kolodner RD. A hereditary nonpolyposis colorectal carcinoma case associated with hypermethylation of the MLH1 gene in normal tissue and loss of heterozygosity of the unmethylated allele in the resulting microsatellite instability-high tumor. Cancer Res 2002;62:3925-8.

5. Hitchins M, Williams R, Cheong K, Halani N, Lin VA, Packham D, Ku S, Buckle A, Hawkins N, Burn J, Gallinger S, Goldblatt J, Kirk J, Tomlinson I, Scott R, Spigelman A, Suter C, Martin D, Suthers G, Ward R. MLH1 germline epimutations as a factor in hereditary nonpolyposis colorectal cancer. Gastroenterology 2005;129:1392-9.

6. Miyakura Y, Sugano K, Akasu T, Yoshida T, Maekawa M, Saitoh S, Sasaki H, Nomizu T, Konishi F, Fujita S, Moriya Y, Nagai H. Extensive but hemiallelic methylation of the hMLH1 promoter region in early-onset sporadic colon cancers with microsatellite instability. Clin Gastroenterol Hepatol 2004;2:147-56.

7. Suter CM, Martin DI, Ward RL. Germline epimutation of MLH1 in individuals with multiple cancers. Nat Genet 2004;36:497-501.

8. Deng G, Bell I, Crawley S, Gum J, Terdiman JP, Allen BA, Truta B, Sleisenger MH, Kim YS. BRAF mutation is frequently present in sporadic colorectal cancer with methylated hMLH1, but not in hereditary nonpolyposis colorectal cancer. Clin Cancer Res 2004:10:191-5

9. Castillejo A, Hernández-Illán E, Rodriguez-Soler M, Pérez-Carbonell L, Egoavil C, Barberá VM, Castillejo MI, Guarinos C, Martínez-de-Dueñas E, Juan MJ, SánchezHeras AB, García-Casado Z, Ruiz-Ponte C, Brea-Fernández A, Juárez M, Bujanda L, Clofent J, Llor X, Andreu M, Castells A, Carracedo A, Alenda C, Payá A, Jover R, Soto JL. Prevalence of MLH1 constitutional epimutations as a cause of Lynch syndrome in unselected versus selected consecutive series of patients with colorectal cancer. J Med Genet 2015;52:498-502.

10. Crucianelli F, Tricarico R, Turchetti D, Gorelli G, Gensini F, Sestini R, Giunti L, Pedroni M, Ponz de Leon M, Civitelli S, Genuardi M. MLH1 constitutional and somatic methylation in patients with MLH1 negative tumors fulfilling the revised Bethesda criteria. Epigenetics 2014;9:1431-8.

11. Kidambi TD, Blanco A, Van Ziffle J, Terdiman JP. Constitutional MLH1 methylation presenting with colonic polyposis syndrome and not Lynch syndrome. Fam Cancer 2016;15:275-80.

12. Morak M, Schackert HK, Rahner N, Betz B, Ebert M, Walldorf C, Royer-Pokora B, Schulmann K, von Knebel-Doeberitz M, Dietmaier W, Keller G, Kerker B, Leitner G, Holinski-Feder E. Further evidence for heritability of an epimutation in one of 12 cases with MLH1 promoter methylation in blood cells clinically displaying HNPCC. Eur J Hum Genet 2008:16:804-11.

13. Pineda $M$, Mur $P$, Iniesta $M D$, Borràs $E$, Campos $O$, Vargas $G$, Iglesias $S$, Fernández A, Gruber SB, Lázaro C, Brunet J, Navarro M, Blanco I, Capellá G. MLH1 methylation screening is effective in identifying epimutation carriers. Eur I Hum Genet 2012;20:1256-64

14. Goel A, Nguyen TP, Leung HC, Nagasaka T, Rhees J, Hotchkiss E, Arnold M, Banerji P, Koi M, Kwok CT, Packham D, Lipton L, Boland CR, Ward RL, Hitchins MP. De novo constitutional MLH1 epimutations confer early-onset colorectal cancer in two new sporadic Lynch syndrome cases, with derivation of the epimutation on the paternal allele in one. Int J Cancer 2011;128:869-78.

15. Hitchins MP. Inheritance of epigenetic aberrations (constitutional epimutations) in cancer susceptibility. Adv Genet 2010;70:201-43.

16. Hitchins MP, Rapkins RW, Kwok CT, Srivastava S, Wong JJ, Khachigian LM, Polly P, Goldblatt J, Ward RL. Dominantly inherited constitutional epigenetic silencing of MLH1 in a cancer-affected family is linked to a single nucleotide variant within the 5'UTR. Cancer Cell 2011;20:200-13.
17. Mayer W, Niveleau A, Walter J, Fundele R, Haaf T. Demethylation of the zygotic paternal genome. Nature 2000;403:501-2.

18. Crépin M, Dieu MC, Lejeune S, Escande F, Boidin D, Porchet N, Morin G, Manouvrier S, Mathieu M, Buisine MP. Evidence of constitutional MLH1 epimutation associated to transgenerational inheritance of cancer susceptibility. Hum Mutat 2012;33:180-8.

19. Hitchins MP, Wong JJ, Suthers G, Suter CM, Martin DI, Hawkins NJ, Ward RL. Inheritance of a cancer-associated MLH1 germ-line epimutation. N Eng/ J Med 2007; 356:697-705.

20. Shoemaker R, Deng J, Wang W, Zhang K. Allele-specific methylation is prevalent and is contributed by CpG-SNPs in the human genome. Genome Res 2010;20:883-9.

21. Cini G, Carnevali I, Quaia M, Chiaravalli AM, Sala P, Giacomini E, Maestro R, Tibiletti $M G$, Viel A. Concomitant mutation and epimutation of the MLH1 gene in a Lynch syndrome family. Carcinogenesis 2015;36:452-8.

22. Gylling $A$, Ridanpää $M$, Vierimaa $O$, Aittomäki $K$, Avela K, Kääriäinen $H$, Laivuori $H$, Pöyhönen M, Sallinen SL, Wallgren-Pettersson C, Järvinen HJ, Mecklin JP, Peltomäki P. Large genomic rearrangements and germline epimutations in Lynch syndrome. Int J Cancer 2009:124:2333-40.

23. Morak M, Koehler U, Schackert HK, Steinke V, Royer-Pokora B, Schulmann K, Kloor M, Höchter W, Weingart J, Keiling C, Massdorf T, Holinski-Feder E. German HNPCC consortium. Biallelic MLH1 SNP CDNA expression or constitutional promoter methylation can hide genomic rearrangements causing Lynch syndrome. J Med Genet 2011;48:513-9.

24. Kwok CT, Vogelaar IP, van Zelst-Stams WA, Mensenkamp AR, Ligtenberg MJ, Rapkins RW, Ward RL, Chun N, Ford JM, Ladabaum U, McKinnon WC, Greenblatt MS, Hitchins MP. The MLH1 c.-27C $>$ A and c.85G $>$ T variants are linked to dominantly inherited MLH1 epimutation and are borne on a European ancestral haplotype. Eur J Hum Genet 2014;22:617-24.

25. Ward RL, Dobbins T, Lindor NM, Rapkins RW, Hitchins MP. Identification of constitutional MLH1 epimutations and promoter variants in colorectal cancer patients from the Colon Cancer Family Registry. Genet Med 2013;15:25-35.

26. Green RC, Green AG, Simms M, Pater A, Robb JD, Green JS. Germline hMLH1 promoter mutation in a Newfoundland HNPCC kindred. Clin Genet 2003:64:220-7.

27. Hesson LB, Packham D, Kwok CT, Nunez AC, Ng B, Schmidt C, Fields M, Wong JW, Sloane MA, Ward RL. Lynch syndrome associated with two MLH1 promoter variants and allelic imbalance of MLH1 expression. Hum Mutat 2015;36:622-30.

28. Grabowski M, Mueller-Koch Y, Grasbon-Frodl E, Koehler U, Keller G, Vogelsang H, Dietmaier W, Kopp R, Siebers U, Schmitt W, Neitzel B, Gruber M, Doerner C, Kerker B, Ruemmele P, Henke G, Holinski-Feder E. Deletions account for $17 \%$ of pathogenic germline alterations in MLH1 and MSH2 in hereditary nonpolyposis colorectal cancer (HNPCC) families. Genet Test 2005;9:138-46.

29. Müller-Koch Y, Kopp R, Lohse P, Baretton G, Stoetzer A, Aust D, Daum J, Kerker B, Gross M, Dietmeier W, Holinski-Feder E. Sixteen rare sequence variants of the hMLH1 and hMSH2 genes found in a cohort of 254 suspected HNPCC (hereditary nonpolyposis colorectal cancer) patients: mutations or polymorphisms? Eur J Med Res 2001;6:473-82.

30. Don RH, Cox PT, Wainwright BJ, Baker K, Mattick JS. 'Touchdown' PCR to circumvent spurious priming during gene amplification. Nucleic Acids Res 1991;19:4008.

31. den Dunnen JT, Dalgleish R, Maglott DR, Hart RK, Greenblatt MS, McGowan-Jordan J, Roux AF, Smith T, Antonarakis SE, Taschner PE. HGVS recommendations for the description of sequence variants: 2016 update. Hum Mutat 2016;37:564-9.

32. Farré D, Roset R, Huerta M, Adsuara JE, Roselló L, Albà MM, Messeguer X. Identification of patterns in biological sequences at the ALGGEN server: PROMO and MALGEN. Nucleic Acids Res 2003:31:3651-3.

33. Ito E, Yanagisawa $Y$, Iwahashi $Y$, Suzuki $Y$, Nagasaki H, Akiyama $Y$, Sugano $S$, Yuasa $Y$, Maruyama K. A core promoter and a frequent single-nucleotide polymorphism of the mismatch repair gene hMLH1. Biochem Biophys Res Commun 1999;256:488-94.

34. Arita M, Zhong X, Min Z, Hemmi H, Shimatake H. Multiple sites required for expression in $5^{\prime}$-flanking region of the hMLH1 gene. Gene 2003;306:57-65.

35. Quaresima B, Faniello MC, Baudi F, Cuda G, Grandinetti C, Tassone P, Costanzo F, Venuta S. Transcriptional regulation of the mismatch repair gene hMLH1. Gene 2001:275:261-5.

36. Warnick CT, Dabbas B, Ilstrup SJ, Ford CD, Strait KA. Cell type-dependent regulation of hMLH1 promoter activity is influenced by the presence of multiple redundant elements. Mol Cancer Res 2003:1:610-8.

37. Deng G, Chen A, Pong E, Kim YS. Methylation in hMLH1 promoter interferes with its binding to transcription factor $\mathrm{CBF}$ and inhibits gene expression. Oncogene 2001;20:7120-7

38. Nakamura H, Tanimoto K, Hiyama K, Yunokawa M, Kawamoto T, Kato Y, Yoshiga K, Poellinger L, Hiyama E, Nishiyama M. Human mismatch repair gene, MLH1, is transcriptionally repressed by the hypoxia-inducible transcription factors, DEC1 and DEC2. Oncogene 2008;27:4200-9.

39. Kuiper RP, Vissers LE, Venkatachalam R, Bodmer D, Hoenselaar E, Goossens M, Haufe A, Kamping E, Niessen RC, Hogervorst FB, Gille JJ, Redeker B, Tops CM, van Gijn $M E$, van den Ouweland AM, Rahner N, Steinke V, Kahl P, Holinski-Feder E, Morak M, Kloor M, Stemmler S, Betz B, Hutter P, Bunyan DJ, Syngal S, Culver JO, Graham T, Chan TL, Nagtegaal ID, van Krieken JH, Schackert HK, Hoogerbrugge N, van Kessel AG, Ligtenberg MJ. Recurrence and variability of germline EPCAM deletions in Lynch syndrome. Hum Mutat 2011;32:407-14. 
40. Blewitt ME, Vickaryous NK, Paldi A, Koseki H, Whitelaw E. Dynamic reprogramming of DNA methylation at an epigenetically sensitive allele in mice. PLoS Genet 2006;2:e49.

41. Hesson LB, Patil V, Sloane MA, Nunez AC, Liu J, Pimanda JE, Ward RL. Reassembly of nucleosomes at the MLH1 promoter initiates resilencing following decitabine exposure. PLoS Genet 2013;9:e1003636.

42. Shin $\mathrm{KH}$, Shin JH, Kim JH, Park JG. Mutational analysis of promoters of mismatch repair genes hMSH2 and hMLH1 in hereditary nonpolyposis colorectal cancer and early onset colorectal cancer patients: identification of three novel germ-line mutations in promoter of the hMSH2 gene. Cancer Res 2002;62:38-42.

43. Thompson BA, Spurdle AB, Plazzer JP, Greenblatt MS, Akagi K, Al-Mulla F, Bapat B, Bernstein I, Capellá G, den Dunnen JT, du Sart D, Fabre A, Farrell MP, Farrington SM, Frayling IM, Frebourg T, Goldgar DE, Heinen CD, Holinski-Feder E, Kohonen-Corish M, Robinson KL, Leung SY, Martins A, Moller P, Morak M, Nystrom M, Peltomaki P, Pineda M, Qi M, Ramesar R, Rasmussen LJ, Royer-Pokora B, Scott RJ, Sijmons R, Tavtigian SV, Tops CM, Weber T, Wijnen J, Woods MO, Macrae F, Genuardi M. Application of a 5-tiered scheme for standardized classification of 2,360 unique mismatch repair gene variants in the InSiGHT locus-specific database. Nat Genet 2014;46:107-15.

44. Richards CS, Bale S, Bellissimo DB, Das S, Grody WW, Hegde MR, Lyon E, Ward BE. Molecular Subcommittee of the ACMG Laboratory Quality Assurance Committee. ACMG recommendations for standards for interpretation and reporting of sequence variations: revisions 2007. Genet Med 2008;10:294-300.
45. Liu Q, Thompson BA, Ward RL, Hesson LB, Sloane MA. Understanding the pathogenicity of noncoding mismatch repair gene promoter variants in Lynch syndrome. Hum Mutat 2016;37:417-26.

46. Yan H, Jin H, Xue G, Mei Q, Ding F, Hao L, Sun SH. Germline hMSH2 promoter mutation in a Chinese HNPCC kindred: evidence for dual role of LOH. Clin Genet 2007;72:556-61.

47. Perera S, Mrkonjic M, Rawson JB, Bapat B. Functional effects of the MLH1-93G $>A$ polymorphism on MLH1/EPM2AIP1 promoter activity. Oncol Rep 2011:25:809-15.

48. Lee SC, Guo JY, Lim R, Soo R, Koay E, Salto-Tellez M, Leong A, Goh BC. Clinical and molecular characteristics of hereditary non-polyposis colorectal cancer families in Southeast Asia. Clin Genet 2005;68:137-45.

49. Nilbert M, Wikman FP, Hansen TV, Krarup HB, Orntoft TF, Nielsen FC, Sunde L, Gerdes AM, Cruger D, Timshel S, Bisgaard ML, Bernstein I, Okkels H. Major contribution from recurrent alterations and MSH6 mutations in the Danish Lynch syndrome population. Fam Cancer 2009;8:75-83.

50. Fredriksson H, Ikonen T, Autio V, Matikainen MP, Helin HJ, Tammela TL, Koivisto PA, Schleutker J. Identification of germline MLH1 alterations in familial prostate cancer. Eur J Cancer 2006;42:2802-6.

51. Zavodna K, Bujalkova M, Krivulcik T, Alemayehu A, Skorvaga M, Marra G, Fridrichova I, Jiricny J, Bartosova Z. Novel and recurrent germline alterations in the MLH1 and MSH2 genes identified in hereditary nonpolyposis colorectal cancer patients in Slovakia. Neoplasma 2006;53:269-76. 